\title{
sciendo
}

Int. J. of Applied Mechanics and Engineering, 2021, vol.26, No.2, pp.143-159

DOI: 10.2478/ijame-2021-0024

\section{TWO-ZONE SIMULATION OF AN AXIAL VANE ROTARY ENGINE CYCLE}

\author{
M.MIRZAEI* \\ Department of Marine Engineering \\ Malek-e-Ashtar University of Technology, Shiraz, IRAN \\ E-mail: m_mirzaei@mut.ac.ir \\ S.M.HASHEMI \\ Department of Automative Engineering \\ Malek-e-Ashtar University of Technology, Shiraz, IRAN \\ B.SARANJAM and A.BINESH \\ Department of Marine Engineering \\ Malek-e-Ashtar University of Technology, Shiraz, IRAN
}

\begin{abstract}
An axial vane rotary engine (AVRE) is a novel type of rotary engines. The engine is a positive displacement mechanism that permits the four "stroke" action to occur in one revolution of the shaft with a minimum number of moving components in comparison to reciprocating engines. In this paper, a two-zone combustion model is developed for a spark ignition AVRE. The combustion chamber is divided into burned and unburned zones and differential equations are developed for the change in pressure and change in temperature in each zone. The modelling is based on equations for energy and mass conservation, equation of state, and burned mass fraction. The assumption is made that both zones are at the same pressure $P$, and the ignition temperature is the adiabatic flame temperature based on the mixture enthalpy at the onset of combustion. The developed code for engine simulation in MATLAB is applied to another engine and there is a good agreement between results of this code and results related to the engine chosen for validation, so the modelling is independent of configuration.
\end{abstract}

Key words: two-zone combustion model, axial vane rotary engine, burned zone, unburned zone, engine simulation.

\section{Introduction}

The axial vane rotary engine (AVRE) consists of a rotor sandwiched between two stators which runs on a shaft housed in bearings in the stator halves. Each stator contains an annular trough of varying depths, such that there are two zones of maximum depth in each trough. The depth varies cycloidally between these zones, and each minimum depth zone is offset 90 degrees from each maximum depth zone. The two stators are out of phase with one another by 90 degrees; that is, the deepest section of one stator is opposite the shallowest of the other. In the present design, the rotor carries twelve vanes, set at 30 degree intervals that are able to translate axially through slots in the rotor. The vanes with vane seals are used to seal the base and the walls of the troughs which protrude into the troughs in the half stators. The volume of the air-fuel mixture is trapped between the two vanes, the rotor surface, and the trough surface changes as the rotor turns relative to the stators. Two compression "strokes" and two expansion "strokes" are realized for each chamber per revolution, thus permitting a four "stroke" cycle operation [1]. The design of the mechanism is such that either spark ignition or compression ignition configurations are possible. Figure 1 is a cut-away solid model of the engine.

\footnotetext{
${ }^{*}$ To whom correspondence should be addressed
} 
In this article spark ignition configuration of this engine has been studied. Figure 2 is a linear layout of the engine. There is a description of the chamber events in Tab.1.

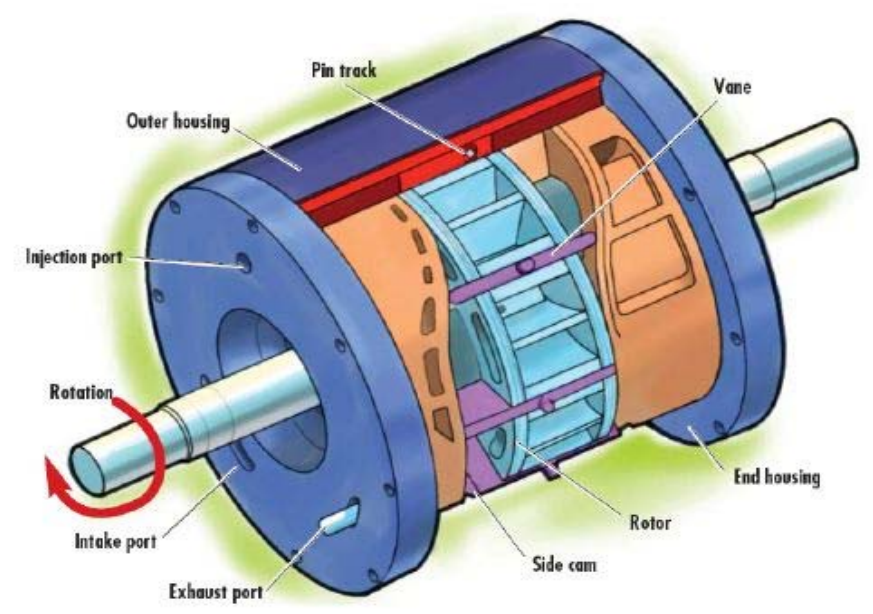

Fig.1.Schematic view of the rotary vane engine [2].

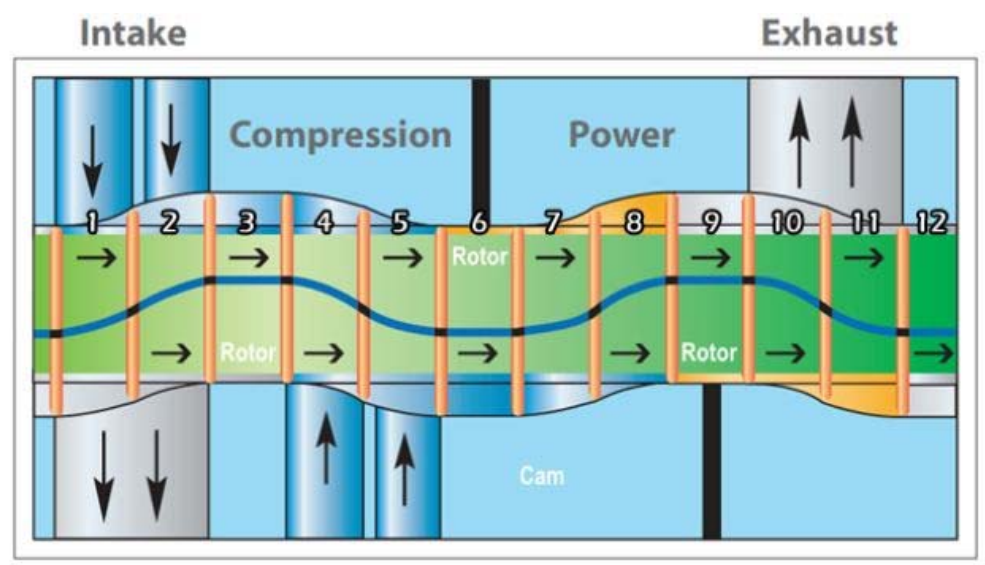

Fig.2. Linear layout of the engine [2].

Table 1. Description of the chamber events.

\begin{tabular}{|c|c|c|c|}
\hline No. & Top Event & No. & Bottom Event \\
\hline 1,2 & Intake & $1,2,3,12$ & Exhaust \\
\hline $3,4,5$ & Compression & 4,5 & Intake \\
\hline $6,7,8$ & Combustion & $6,7,8$ & Compression \\
\hline $9,10,11,12$ & Exhaust & $9,10,11$ & Combustion \\
\hline
\end{tabular}

\section{Literature review}

Combustion modeling of a single cylinder spark ignition engine of the bike was conducted by $\mathrm{Ch} . \mathrm{K}$. Patel et al. [1] using computational fluid dynamics for predicting the turbulent flame speed at different equivalence ratio and engine speed. A premixed combustion model is used in this study. The methane gas was 
taken as fuel and single oxidation of methane with oxygen to form carbon dioxide and water vapor. Prediction of turbulent flame speed for premixed combustion was done in FLUENT software [1].

A single-zone zero-dimensional model for any hydrocarbon fuel based on Wiebe heat release function was implemented in Simulink to test the performance of the spark ignition engine by A. J. Chaudharia et al. [2] Annand's model for convective heat losses was taken for modeling of engine cycle. The Simulink results are validated with experimental results from literature [2].

An exergy analysis of using the gaseous fuels in spark ignition engines was performed by Sezer et al. [3]. A quasi-dimensional two-zone thermodynamic cycle model was used for this purpose. The intake and exhaust processes were computed by a simple approximation method, and the processes (that are compression, combustion, and expansion) were simulated in detail. The turbulent flame propagation process was used for the combustion simulation. The second law of thermodynamic was applied to the cycle model to perform the exergy analysis. The exergy transfers associated with heat, work, and exhaust, the irreversibilities, thermomechanical exergy, fuel chemical exergy, and total exergy were computed in the exergy analysis [3].

First and second thermodynamic law analyses were applied to spark ignition engines modeling and emission prediction by Amaya et al. [4]. A mathematical and numerical model of flow and combustion process for spark ignition engines was developed using the principles of the first and second laws of thermodynamic. Availability (exergy) analysis was applied to the cylinder of a spark ignition engine during the combustion process using a two-zone combustion model [4].

A computation fluid dynamics simulation of a spark ignition engine for gaseous fuels by varying crank angles was performed by Nagamani et al. [5]. Methane was used as a fuel in this study. CFD analysis was made in Ansys IC engine module in the component manifold [5].

A single-zone heat release model was developed in MATLAB by J. L. Cuddihly [6] to predict engine performance and efficiencies on a Yamaha YZ250F engine. The general single-zone model was expanded to include friction losses as a function of engine speed, combustion efficiencies at different operating points, temperature-dependent thermodynamic properties, and residual gas fractions. The single-zone model was then split into a two-zone model using burned and unburned volume fractions. The elevated burned zone temperature provided by the two-zone model was used to predict $\mathrm{NO}$ and $\mathrm{HC}$ emissions [6].

A math-based spark ignition engine modeling including emission prediction for control applications was performed by Adibi-Asl et al [7]. In the mentioned research, a physics-based model of an SI engine was presented which consisted of different sub-models including throttle body and manifold model, four-stroke quasi-dimensional thermodynamic model of gas exchange and power cycles, two-zone combustion and flame propagation model, emission gases model based on the chemical kinetics equations and mechanical torque model [7].

A study of spark ignition engine combustion model for the analysis of cyclic variation and combustion stability at lean operating conditions was performed by $\mathrm{H}$. Wuo [8]. A fundamental combustion model for a spark-ignition engine was studied in this report. The model was implemented in SIMULINK to simulate engine outputs (mass fraction burned and in-cylinder pressure) under various engine operation conditions. The combustion model includeed a turbulent propagation and eddy burning processes based on literature. The turbulence propagation and eddy burning processes are simulated by a zero-dimensional method and the flame is assumed as sphere. To predict pressure, temperature and other in-cylinder variables, a two-zone thermodynamic model was used [8].

A symbolic sensitivity analysis of a math-based spark ignition engine with a two-zone combustion model was conducted by Adibi asl et al. [9]. The math-based spark ignition (SI) engine model was presented for fast simulation with enough fidelity to predict in-cylinder thermodynamic properties at each crank angle. The quasi-dimensional modeling approach is chosen to simulate four-stroke operation. The combustion model was formulated based on the two-zone combustion theory with a turbulent flame propagation model [9].

A bi-fuel SI engine model for analysis and optimization was presented by Rezapour et al. [10]. It is based on the two-zone combustion model, and it has the ability to simulate turbulent combustion. The model is capable of predicting the cylinder temperature and pressure, heat transfer, brake work, brake thermal and volumetric efficiency, brake torque, brake specific fuel consumption (BSFC), brake mean effective pressure (BMEP), concentration of CO2, brake specific CO (BSCO) and brake specific NOx (BSNOx) [10]. 


\section{Cycle simulation using a two-zone combustion model}

\subsection{Equivalent engine determination}

Previous studies on a piston engine have shown that the chamber pressure, gas temperature, and heat loss can be well predicted by using a zero dimensional model [11]. Zero dimensional, thermodynamic codes model the overall in-chamber mass transfer, heat transfer, and energy release rate by dividing the combustion chamber into one, two, or multiple premixed zones. A zero dimensional model of a reciprocating piston engine represents the combustion chamber geometry in a simplified manner such that the chamber is represented by a cylinder with a specified stroke, bore, and minimum surface area.

In zero dimensional modelling, the most important feature is the volume change with crank angle, or shaft angle in the AVRE, since the combustion chamber is represented with simplified geometry. With respect to reference [2], it has been tried to determine a four stroke reciprocating piston engine equivalent to the AVRE engine.

It should be mentioned that the AVRE completes one cycle every 360 degrees, while 720 degrees are required to complete one cycle of a four stroke reciprocating piston engine. If both engines are considered to perform one cycle every 720 degrees, the volume change with crank angle will be nearly identical for both engines which can be observed in Fig.3.

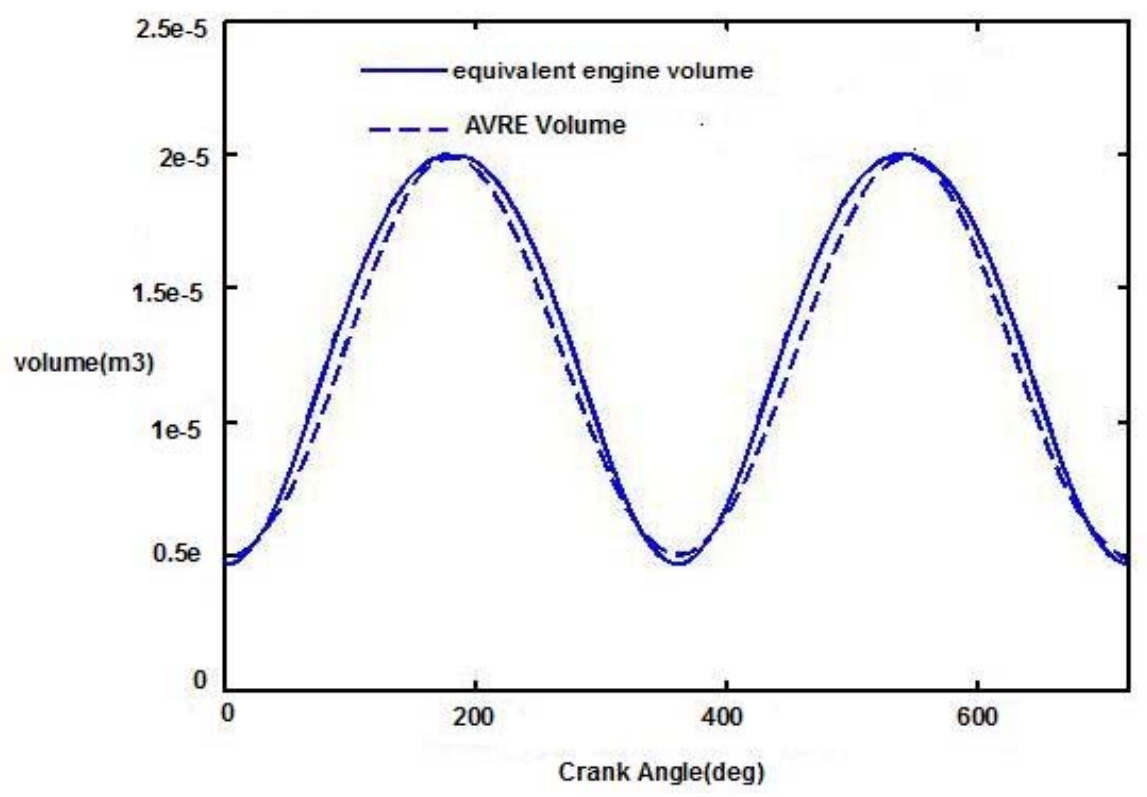

Fig.3. Comparison between AVRE and equivalent engine volume.

A list of key parameters of equivalent piston engine can be observed in Tab.2.

Table 2. Equivalent piston engine key parameters

\begin{tabular}{|l|c|}
\hline \multicolumn{1}{|c|}{ Parameter } & Value \\
\hline Cylinder bore $(\mathrm{mm})$ & 0.0255 \\
\hline Stroke $(\mathrm{mm})$ & 0.03 \\
\hline Connecting rod length $(\mathrm{mm})$ & 50 \\
\hline Clearance volume $(\mathrm{m} 3)$ & $4.71 e-6$ \\
\hline Swept volume $(\mathrm{m} 3)$ & $1.53 e-5$ \\
\hline
\end{tabular}


To validate the zero dimensional model, a two zone model developed for the equivalent engine, has been used for a spark ignition engine analyzed in [3], and according to the results it can be concluded that the model is independent of configuration.

\subsection{Mathematical model of the fuel-air-residual gas}

For the present study, a zero-dimensional combustion model is employed. The combustion chamber is divided into two zones consisting of unburned gas which is a mixture of fuel, air and residuals and burned gas (b) which is a mixture of ten product species. It has been assumed that burned and unburned gases have uniform compositions. The burned gases are assumed to be in chemical equilibrium during combustion.

In this section, a homogeneous fuel-air cycle in which the fuel and air are completely mixed prior to the commencement of combustion, is discussed. The modeling is based on equations for energy and mass conservation, equation of state, and burned mass fraction. An assumption is made that both zones are at the same pressure, and the ignition temperature is the adiabatic flame temperature based on the mixture enthalpy at the onset of combustion. The analysis includes heat loss to the combustion chamber surfaces, and the blowby mass loss past the rings.

A finite heat release function is used to express the fraction of heat added over a given crank angle change which represents the mass fraction $(x)$ of the burned, cylinder contents. The solution procedure is a simultaneous integration of a set of ordinary differential equations for $(P),\left(T_{u}\right),\left(T_{b}\right)$, and subsequent calculation of net work $(W)$ and heat $\operatorname{loss}(Q)$.

The most important parts of the model developed are discussed in what follows. As mentioned earlier, in this research a combustion model is developed for a reciprocating spark ignition equivalent to the rotary AVRE engine. In reciprocating engines there is residual gas mixed with the fuel and air, since not all of the combustion gases leave the cylinder, therefore in this research a combustion model is developed. For this purpose it would be necessary to determine the composition of the fuel-air-residual mixture for analysis of compression stroke and later for analysis of unburned mixture ahead of the flame. It is assumed that residual gas is at a low enough temperature $(T<1000 K)$ so that species relations in Tab.1. would specify its composition. The fuel-air-residual gas mixture will contain both reactants and products

$$
n_{0}^{\prime} \mathrm{C}_{a} \mathrm{H}_{b} \mathrm{O}_{c} \mathrm{~N}_{d}+n_{4}^{\prime} \mathrm{O}_{2}+n_{3}^{\prime} \mathrm{N}_{2} \rightarrow n_{1}^{\prime \prime} \mathrm{CO}_{2}+n_{2}^{\prime \prime} \mathrm{H}_{2} \mathrm{O}+n_{3}^{\prime \prime} \mathrm{N}_{2}+n_{4}^{\prime \prime} \mathrm{O}_{2}+n_{5}^{\prime \prime} \mathrm{CO}+n_{6}^{\prime \prime} \mathrm{H}_{2} \text {. }
$$

Table 3. Low temperature combustion products.

\begin{tabular}{|c|c|c|c|}
\hline Species & $n_{i}$ & $\phi \leq 1$ & $\phi>1$ \\
\hline $\mathrm{CO}_{2}$ & $n_{1}$ & $a$ & $a-n_{5}$ \\
\hline $\mathrm{H}_{2} \mathrm{O}$ & $n_{2}$ & $b / 2$ & $(b / 2)-d_{1}+n_{5}$ \\
\hline $\mathrm{N}_{2}$ & $n_{3}$ & $(d / 2)+3.76\left(a_{s} / \phi\right)$ & $(d / 2)+3.76\left(a_{s} / \phi\right)$ \\
\hline $\mathrm{O}_{2}$ & $n_{4}$ & $a_{s}((1 / \phi)-1)$ & 0 \\
\hline $\mathrm{CO}$ & $n_{5}$ & 0 & $n_{5}$ \\
\hline $\mathrm{H}_{2}$ & $n_{6}$ & 0 & $d_{1}-n_{5}$ \\
\hline
\end{tabular}

The residual mole fraction $\left(y_{r}\right)$ is: 


$$
y_{r}=\frac{n_{r}}{n_{f a}+n_{r}}=\frac{1}{\frac{n_{f a}}{n_{r}}+1} .
$$

Since $f=\left(\frac{m_{r}}{m}\right)$ it can be written that:

$$
\frac{m_{f a}}{m_{r}}=\frac{1}{f}-1
$$

and

$$
\frac{m_{f a}}{n_{r}}=\frac{m_{f a}}{m_{r}} \frac{M_{r}}{M_{f a}}=\frac{m_{f a}}{m_{r}} \frac{M^{\prime \prime}}{M}
$$

Upon substitution, the residual mole fraction, $\left(y_{r}\right)$, is:

$$
y_{r}=\left[1+\frac{M^{\prime \prime}}{M^{\prime}}\left(\frac{1}{f}-1\right)\right]^{-1} .
$$

The species mole fractions, $\left(y_{i}\right)$, are:

$$
y_{i}=\frac{n_{i}}{N}=\frac{n_{i}}{n_{f a}} y_{f a}+\frac{n_{i}}{n_{r}} y_{r}
$$

since

$$
y_{f a}=1-y_{r}, \quad y_{i}^{\prime}=\frac{n_{i}}{n_{f a}}, \quad y_{i}^{\prime \prime}=\frac{n_{i}}{n_{r}}
$$

the species mole fractions are

$$
y_{i}=\left(1-y_{r}\right) y_{i}^{\prime}+y_{r} y_{i}^{\prime \prime} \quad i=0.6 .
$$

Since neither the residual mole fraction $\left(y_{i}\right)$ nor the reactant mole fractions $\left(y_{i}^{\prime}\right)$ depend on temperature, differentiation of $\mathrm{Eq}(3.8)$ with respect to temperature yields:

$$
\frac{\partial y_{i}}{\partial T}=y_{r} \frac{\partial y_{i}^{\prime \prime}}{\partial T}=y_{r} \frac{1}{N} \frac{\partial n_{i}}{\partial T}
$$

Inspection of Tab.3 indicates that for lean combustion, none of these six partial derivatives depend on temperature. Hence, it can be written: 


$$
\begin{aligned}
& \frac{\partial y_{i}}{\partial T}=0, \\
& \frac{\partial y_{i}}{\partial T}=y_{r} \frac{1}{N} \frac{\partial n_{i}}{\partial n_{5}} \frac{\partial n_{5}}{\partial K} \frac{\partial K}{\partial T} .
\end{aligned}
$$

In simulation performed in this paper, the fuel is initially mixed with air with an equivalence ratio $(\phi)$. The composition and thermodynamic properties of the product mixture, which is assumed to be in equilibrium at temperature $(T)$ and pressure $(P)$, are to be determined.

In this section, a numerical solution for the properties of equilibrium combustion of products based on an equilibrium constant method explained in [11] is presented. The use of equilibrium constants is also based on the minimization of the Gibbs free energy of the gas mixture; according to [11] it is understood that if $(\phi<3)$ the only product species of importance resulting from dissociation are $\mathrm{O}, \mathrm{H}, \mathrm{OH}$, and NO. Therefore the following reaction is considered:

$$
\begin{aligned}
& \mathrm{C}_{a} \mathrm{H}_{b} \mathrm{O}_{c} \mathrm{~N}_{d}+\frac{a_{s}}{\phi}\left(\mathrm{O}_{2} 3.76 \mathrm{~N}_{2}\right) \rightarrow \\
& \rightarrow n_{1} \mathrm{CO}_{2}+n_{2} \mathrm{H}_{2} \mathrm{O}+n_{3} \mathrm{~N}_{2}+n_{4} \mathrm{O}_{2}+n_{5} \mathrm{CO}+n_{6} \mathrm{H}_{2}+n_{7} \mathrm{H}+n_{8} \mathrm{O}+n_{9} \mathrm{OH}+n_{10} \mathrm{NO} .
\end{aligned}
$$

Atom balancing yields the following four equations:

$$
\begin{aligned}
& C: \quad a=\left(y_{1}+y_{5}\right) N, \\
& H: \quad b=\left(2 y_{2}+2 y_{6}+y_{7}+y_{9}\right) N, \\
& O: \quad c+2 a_{s} / \phi=\left(2 y_{1}+y_{2}+2 y_{4}+y_{5}+y_{8}+y_{90}+y_{10}\right), \\
& N: \quad d+7.25 a_{s} / \phi=\left(2 y_{3}+y_{10}\right) N
\end{aligned}
$$

where $(N)$ is the total number of moles. By definition, the mole fractions sum is 1 :

$$
\sum_{i=1}^{10} y_{i}=1
$$

From these equations, three constants are defined:

$$
d_{1}=\frac{b}{a}, \quad d_{2}=\frac{c}{a}+2 \frac{a_{s}}{\phi a}, \quad d_{3}=\frac{d}{a}+\frac{7.52 a_{s}}{\phi a} .
$$

Upon substitution into the atom balance equations, and with some rearrangement: 


$$
\begin{aligned}
& 2 y_{2}+2 y_{6}+y_{7}+y_{9}+d_{1} y_{1}-d_{1} y_{5}=0, \\
& 2 y_{1}+y_{2}+2 y_{4}+y_{5}+y_{8}+y_{9}+y_{10}-d_{2} y_{1}-d_{2} y_{5}=0, \\
& 2 y_{3}+y_{10}-d_{3} y_{1}-d_{3} y_{5}=0, \\
& \sum y_{i}=1 .
\end{aligned}
$$

Six gas-phase equilibrium reactions are introduced. These reactions include the dissociation of hydrogen, oxygen, water, and carbon dioxide, and the formation of $\mathrm{OH}$ and $\mathrm{NO}$ :

$$
\begin{aligned}
& \frac{1}{2} H_{2} \rightleftharpoons H, \quad K_{1}=\frac{y_{7} P^{1 / 2}}{y_{6}^{1 / 2}}, \\
& \frac{1}{2} \mathrm{O}_{2} \rightleftharpoons \mathrm{O}, \quad K_{2}=\frac{y_{8} P^{1 / 2}}{y_{4}^{1 / 2}}, \\
& \frac{1}{2} \mathrm{H}_{2}+\frac{1}{2} \mathrm{O}_{2} \rightleftharpoons \mathrm{OH}, \quad K_{3}=\frac{y_{9}}{y_{4}^{1 / 2} y_{6}^{1 / 2}}, \\
& \frac{1}{2} \mathrm{O}_{2}+\frac{1}{2} \mathrm{~N}_{2} \rightleftharpoons \mathrm{NO}, \quad K_{4}=\frac{y_{10}}{y_{4}^{1 / 2} y_{3}^{1 / 2}}, \\
& \mathrm{H}_{2}+\frac{1}{2} \mathrm{O}_{2} \rightleftharpoons \mathrm{H}_{2} \mathrm{O}, \quad K_{5}=\frac{y_{2}}{y_{4}^{1 / 2} y_{6}^{1 / 2} P^{1 / 2}}, \\
& \mathrm{CO}+\frac{1}{2} \mathrm{O}_{2} \rightleftharpoons \mathrm{CO}_{2}, \quad K_{6}=\frac{y_{1}}{y_{4}^{1 / 2} y_{5} P^{1 / 2}} .
\end{aligned}
$$

Equilibrium constants $K_{i}(T)$ are curve fitted to JANAF Table data for the temperature range $(600<T<4000)$ in reference [11] and the result is the following expression:

$$
\log _{10}^{K_{i}(T)}=A_{i} \ln (T / 1000)+\frac{B_{i}}{T}+C_{i}+D_{i}+E_{i} T^{2}
$$

where $(T)$ is in Kelvin. The equilibrium constant $\left(K_{i}\right)$ curve-fit coefficients are listed in a table in [11]. Equations (3.12), (3.13) and (3.16) will yield eleven equations for the eleven unknowns: the ten unknown mole fractions $\left(y_{i}\right)$ and the unknown total product moles $(N)$. Substitution of the six individual equilibrium reaction equations into the atom balance equations results in four equations with four unknowns 
$\left(y_{3}, y_{4}, y_{5}, y_{6}\right)$; these four equations are solved numerically in this paper. On the other hand, the open system energy equation applied to the cylinder contents, is

$$
\begin{aligned}
& \frac{d Q}{d \theta}-P \frac{d V}{d \theta}=\frac{d U}{d \theta}+\frac{\dot{m}_{1} h_{1}}{\omega}, \\
& \frac{d Q}{d \theta}-P \frac{d V}{d \theta}=m \frac{d u}{d \theta}+u \frac{d m}{d \theta}+\frac{\dot{m}_{l} h_{1}}{\omega} .
\end{aligned}
$$

The specific volume $(v)$ of the system is given by

$$
v=\frac{V}{m}=x v_{b}+(1-x) v_{u} .
$$

Since $v=v(T, P)$ the system is given by

$$
\begin{gathered}
\frac{\partial v_{b}}{\partial \theta}=\frac{\partial v_{b}}{\partial T_{b}} \frac{\partial T_{b}}{\partial \theta}+\frac{\partial v_{b}}{\partial P} \frac{\partial P}{\partial \theta} \\
\frac{\partial v_{u}}{\partial \theta}=\frac{\partial v_{u}}{\partial T_{u}} \frac{\partial T_{u}}{\partial \theta}+\frac{\partial v_{u}}{\partial P} \frac{\partial P}{\partial \theta} .
\end{gathered}
$$

Differentiating the equation for the specific volume, Eq.(3.19) and incorporating Eq.(3.20) yield

$$
\begin{aligned}
& \frac{1}{m} \frac{d V}{d \theta}-\frac{V}{m^{2}}=x \frac{d v_{b}}{d \theta}+(1-x) \frac{d v_{u}}{d \theta}+\left(v_{b}-v_{u}\right) \frac{d x}{d \theta} \\
& \frac{1}{m} \frac{d V}{d \theta}+\frac{V C}{m \omega}=x \frac{d v_{b}}{d T_{b}} \frac{d T_{b}}{d \theta}+(1-x) \frac{d v_{u}}{d T_{u}} \frac{d T_{u}}{d \theta}+\left[x \frac{d v_{b}}{d P}\right]
\end{aligned}
$$

The total internal energy $(u)$ of the system is the sum of the internal energy of burned and unburned zones:

$$
u=\frac{U}{m}=x u_{b}+(1-x) u_{u}
$$

where $\left(u_{b}\right)$ is the internal energy of the burned gas at temperature $\left(T_{b}\right)$, and $\left(u_{u}\right)$ is the energy of the burned gas at temperature $\left(T_{u}\right)$. Since $u=u(T, P)$, the chain rule can be applied to both zones:

$$
\begin{aligned}
& \frac{\partial u_{b}}{\partial \theta}=\frac{\partial u_{b}}{\partial T_{b}} \frac{\partial T_{b}}{\partial \theta}+\frac{\partial u_{b}}{\partial P} \frac{\partial P}{\partial \theta}, \\
& \frac{\partial u_{b}}{\partial \theta}=\left(c_{p b}-P \frac{\partial v_{b}}{\partial T_{b}}\right) \frac{\partial T_{b}}{\partial \theta}-\left(T_{b} \frac{\partial v_{b}}{\partial T_{b}}+P \frac{\partial v_{b}}{\partial P}\right) \frac{\partial P}{\partial \theta},
\end{aligned}
$$


similarly

$$
\frac{\partial u_{u}}{\partial \theta}=\left(c_{p u}-P \frac{\partial v_{u}}{\partial T_{u}}\right) \frac{\partial T_{u}}{\partial \theta}-\left(T_{u} \frac{\partial v_{u}}{\partial T_{u}}+P \frac{\partial v_{u}}{\partial P}\right) \frac{\partial P}{\partial \theta} .
$$

The $\left(m \frac{d u}{d \theta}\right)$ term in the energy equation is therefore

$$
\begin{aligned}
& m \frac{d u}{d \theta}=m\left[x \frac{d u_{b}}{d \theta}+(1-x) \frac{d u_{u}}{d \theta}+\left(u_{b}-u_{u}\right) \frac{d x}{d \theta}\right]= \\
& =m x\left(c_{p b}-P \frac{\partial v_{b}}{\partial T_{b}}\right) \frac{\partial T_{b}}{\partial \theta}+m(1-x)\left(c_{p u}-P \frac{\partial v_{u}}{\partial T_{u}}\right) \frac{\partial T_{u}}{\partial \theta}+ \\
& -\left[m x\left(T_{b} \frac{\partial v_{b}}{\partial T_{b}}+P \frac{\partial v_{b}}{\partial P}\right)+m(1-x)\left(T_{u} \frac{\partial v_{u}}{\partial T_{u}}+P \frac{\partial v_{u}}{\partial P}\right)\right] \frac{d P}{d \theta}+m\left(u_{b}-u_{u}\right)
\end{aligned}
$$

The term $\left(u \frac{d m}{d \theta}\right)$ is the blowby term, it can be written that

$$
\frac{d m}{d \theta}=-\frac{\dot{m}_{1}}{\omega}=-\frac{C m}{\omega}
$$

where $(C)$ is the blowby coefficient which is dependent on the ring design. This implies that the mass in the cylinder at a given crank angle $(\theta)$, would be decreased as follows

$$
m(\theta)=m_{1} \exp \left[-C\left(\theta-\theta_{1}\right) / \omega\right]
$$

where $\left(m_{l}\right)$ is the initial mass at the start of compression. The term $\left(\frac{d Q}{d \theta}\right)$ is the heat loss term and it can be written as follows

$$
\frac{d Q}{d \theta}=-\frac{\dot{Q}_{1}}{\omega}=-\frac{-\dot{Q}_{b}-\dot{Q}_{u}}{\omega}
$$

from the burned and unburned gases. The heat loss terms are expressed with a convection equation,

$$
\begin{aligned}
& \dot{Q}_{b}=h A_{b}\left(T_{b}-T_{w}\right), \\
& \dot{Q}_{u}=h A_{u}\left(T_{u}-T_{w}\right)
\end{aligned}
$$

where $(h)$ is the convection heat transfer coefficient, and $\left(A_{b}\right)$ and $\left(A_{u}\right)$ are the areas of the burned and unburned gases in contact with the cylinder walls at temperature $\left(T_{w}\right)$. It is assumed that $\left(h_{u}=h_{b}=h=c t e\right)$. For the areas $\left(A_{b}\right)$ and $\left(A_{u}\right)$ it is supposed that the cylinder area $\left(A_{c}\right)$ can be divided as follows: 


$$
\begin{aligned}
& A_{c}=\frac{\pi b^{2}}{2}+\frac{4 V}{b}, \\
& A_{b}=A_{c} x^{1 / 2}, \\
& A_{u}=A_{c}\left(1-x^{1 / 2}\right) .
\end{aligned}
$$

The fraction of the cylinder area in contact with the burned gas is assumed to be proportional to the square root of the mass fraction burned with respect to the density difference between burned and unburned gas, the burned gas occupies a larger volume fraction of the cylinder than the unburned gas.

In practice, the exponent on $(x)$ may be left as a free parameter to be determined from experiments or a more complicated scheme may be used based on an assumption about the flame shape.

The enthalpy of the mass loss due to blowby $\left(h_{l}\right)$ should be specified. Early in the combustion process, unburned gas leaks past the rings. Late in the combustion process, burned gas leaks past the rings. Since a larger portion of unburned gas will be leaking than the unburned mass fraction, it can be assumed that

$$
h_{1}=\left(1-x^{2}\right) h_{u}+x^{2} h_{b}
$$

where $h_{u}=h\left(T_{u}, P\right)$ and $h_{b}=h\left(T_{b}, P\right)$. The mass fraction burned, $x(\theta)$ is represented by the following finite heat release equation:

$$
\begin{aligned}
& x=0 \quad \text { for } \quad \theta<\theta_{s}, \\
& x=\frac{1}{2}\left(1-\cos \left(\frac{\pi\left(\theta-\theta_{s}\right)}{\theta_{b}}\right)\right), \\
& x=1 \quad \text { for } \quad \theta>\theta_{s}+\theta_{b} .
\end{aligned}
$$

The remaining equation comes from introduction of the unburned gas entropy into the analysis. Treating the unburned gas as an open system losing mass via leakage and combustion, it can be shown that

$$
-\dot{Q}_{u}=\omega m(1-x) T_{u} \frac{d s_{u}}{d \theta} .
$$

Since $s_{u}=s_{u}\left(T_{u}, P\right)$ it follows that

$$
\begin{aligned}
& \frac{\partial s}{\partial \theta}=\frac{\partial s_{u}}{\partial T_{u}} \frac{\partial T_{u}}{\partial \theta}+\frac{\partial s_{u}}{\partial P} \frac{\partial P}{\partial \theta}, \\
& \frac{\partial s}{\partial \theta}=\frac{c_{p u}}{T_{u}} \frac{d T_{u}}{d \theta}+\frac{\partial v_{u}}{\partial T_{u}} \frac{\partial P}{\partial \theta} .
\end{aligned}
$$


Elimination of $\left(\frac{d s_{u}}{d \theta}\right)$ from Eq.(3.37) and Eq.(3.38) gives

$$
c_{p u} \frac{d T_{u}}{d \theta}-T_{u} \frac{\partial v_{u}}{\partial T_{u}} \frac{d P}{d \theta}=\frac{-h A_{u}}{\omega m(1-x)}\left(T_{u}-T_{w}\right) .
$$

For convenience the following variables are defined:

$$
\begin{aligned}
& A=\frac{1}{m}\left(\frac{d V}{d \theta}+\frac{V C}{\omega}\right) \\
& B=\frac{h A_{c}}{\omega m}\left[\frac{1}{c_{p b}} \frac{\partial v_{b}}{\partial T_{b}} x^{1 / 2}\left(T_{b}-T_{w}\right)+\frac{1}{c_{p b}} \frac{\partial v_{u}}{\partial T_{u}}\left(1-x^{1 / 2}\right)\left(T_{u}-T_{w}\right)\right] \\
& C=-\left(v_{b}-v_{u}\right) \frac{d x}{d \theta}-\frac{\partial v_{b}}{\partial T_{b}} \frac{h_{u}-h_{b}}{c_{p b}}\left[\frac{d x}{d \theta}-\frac{\left(x-x^{2}\right) C}{\omega}\right] \\
& D=x\left[\frac{T_{b}}{c_{p b}}\left(\frac{\partial v_{b}}{\partial T_{b}}\right)^{2}+\frac{\partial v_{b}}{\partial P}\right], \\
& E=(1-x)\left[\frac{T_{u}}{c_{p u}}\left(\frac{\partial v_{u}}{\partial T_{u}}\right)^{2}+\frac{\partial v_{u}}{\partial P}\right] .
\end{aligned}
$$

The six equations to be integrated are

$$
\begin{aligned}
& \frac{d P}{d \theta}=\frac{A+B+C}{D+E}, \\
& \frac{d T_{b}}{d \theta}=\frac{-h A_{c}\left(T_{b}-T_{w}\right)}{\omega m c_{p b} x^{1 / 2}}+\frac{T_{b}}{c_{p b}} \frac{\partial v_{b}}{\partial T_{b}} \frac{A+B+C}{D+E}+\frac{h_{u}-h_{b}}{x c_{p b}}\left[\frac{d x}{d \theta}-\left(x-x^{2}\right) \frac{C}{\omega}\right], \\
& \frac{d T_{u}}{d \theta}=\frac{-h A_{c}\left(1-x^{1 / 2}\right)\left(T_{u}-T_{w}\right)}{\omega m c_{p u}(1-x)}+\frac{T_{u}}{c_{p u}} \frac{\partial v_{u}}{\partial T_{u}} \frac{A+B+C}{D+E}, \\
& \frac{d W}{d \theta}=P \frac{d V}{d \theta}, \\
& \frac{d Q_{1}}{d \theta}=\frac{h A_{c}}{\omega}\left[x^{1 / 2}\left(T_{b}-T_{u}\right)+\left(1-x^{1 / 2}\right)\left(T_{u}-T_{w}\right)\right],
\end{aligned}
$$




$$
\frac{d H_{1}}{d \theta}=\frac{C m}{\omega}\left[\left(1-x^{2}\right) h_{u}+x^{2} h_{b}\right] .
$$

The developed code input would be the operational specifications of the engine which are listed in Tab.4.

Table 4. Operational specifications of the simulated engine.

\begin{tabular}{|l|c|}
\hline \multicolumn{1}{|c|}{ Parameter } & Value \\
\hline Fuel & $C_{8} H_{18}$ \\
\hline Compression ratio & 10 \\
\hline Equivalence ratio & 1 \\
\hline Inlet pressure(Kpa) & 101.3 \\
\hline Engine speed(rpm) & 7000 \\
\hline Inlet temperature(K) & 350 \\
\hline Residual fraction & 0.1 \\
\hline Air fuel ratio & 15 \\
\hline
\end{tabular}

\section{Model validation}

Since no experimental data for the AVRE is available at this time, estimates of parameters such as combustion duration, cylinder wall temperature, and intake air temperature have been made. Spark ignition engine cycle simulation has been performed on the equivalent four stroke reciprocating engine of the AVRE engine, with approximately the same cylinder volume variation versus crank angle as this rotary engine. To validate the developed code for zero dimensional simulation of SI engine, this code is used for the four stroke spark ignition engine simulated in [14]. The operational specifications of that engine are listed in Tab.5.

Table 5. Engine operational specifications of engine used for validation [14].

\begin{tabular}{|l|c|}
\hline \multicolumn{1}{|c|}{ Parameter } & Value \\
\hline Clearance Volume $\left(\mathrm{m}^{3}\right)$ & $5.41 \mathrm{e}-5$ \\
\hline Swept Volume $\left(\mathrm{m}^{3}\right)$ & $3.95 e-4$ \\
\hline Compression ratio & 8.3 \\
\hline Equivalence ratio & 1 \\
\hline Start of energy release & $-25 \mathrm{BTDC}$ \\
\hline duration of energy release $(\mathrm{deg})$ & 70 \\
\hline Wall temperature $(\mathrm{K})$ & 400 \\
\hline Engine speed $(\mathrm{rpm})$ & 5000 \\
\hline Cylinder bore $(\mathrm{mm})$ & 86.4 \\
\hline Stroke $(\mathrm{mm})$ & 67.4 \\
\hline
\end{tabular}

Pressure variation versus crank angle is computed using the code developed in this paper for the engine chosen for validation; its result is compared with pressure variation estimation performed in [11] in Fig.4; it can be seen that the developed code has predicted pressure with good accuracy. 


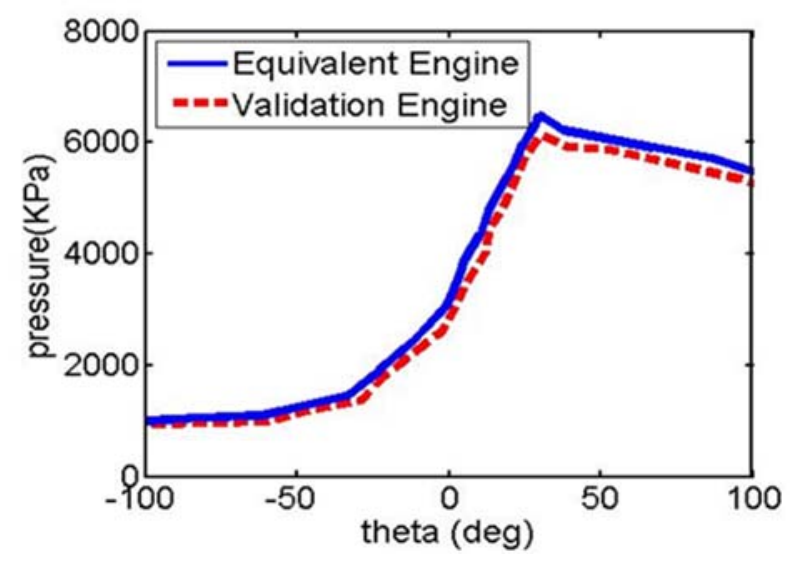

Fig.4. Comparison of pressure variation versus crank angle estimation in this paper and reference [11].

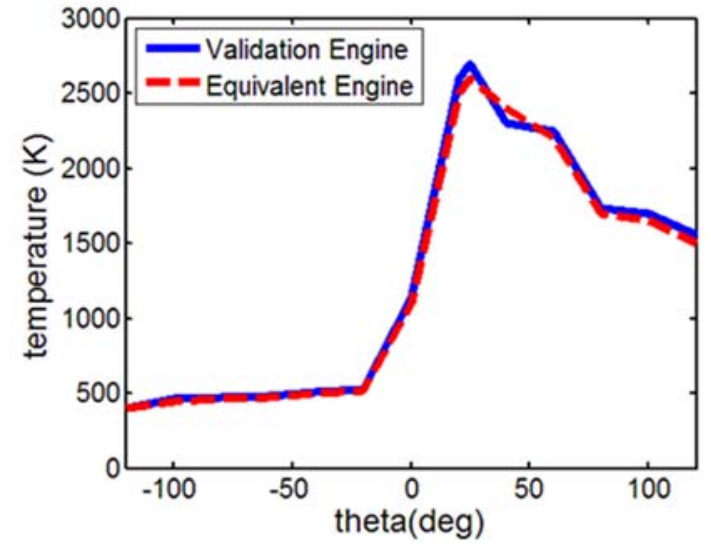

Fig.5.Comparison of temperature variation versus crank angle estimation in this paper and reference [11].

\section{Results and discussions}

Pressure variation versus crank angle is estimated for the equivalent engine which is shown in Fig.6. As it can be seen in this figure the maximum pressure is equal to $7325 \mathrm{kPa}$ which is at 188 degrees in the engine cycle.

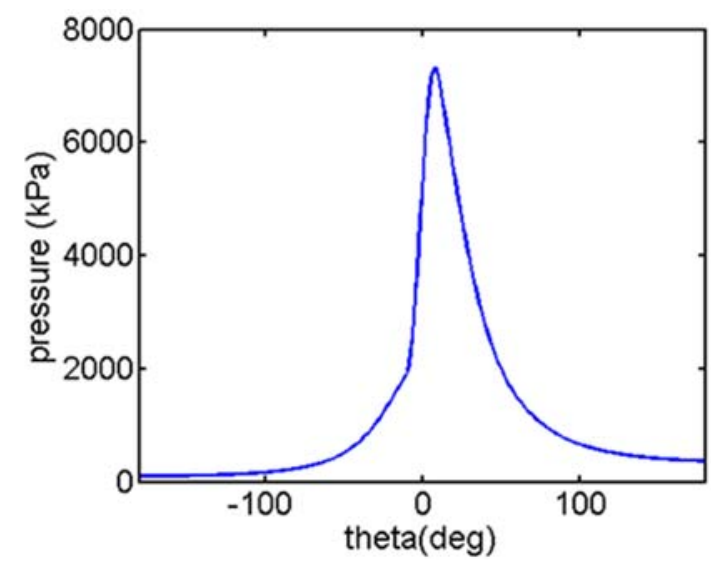

Fig.6. Pressure variation estimation versus crank angle for the equivalent engine.

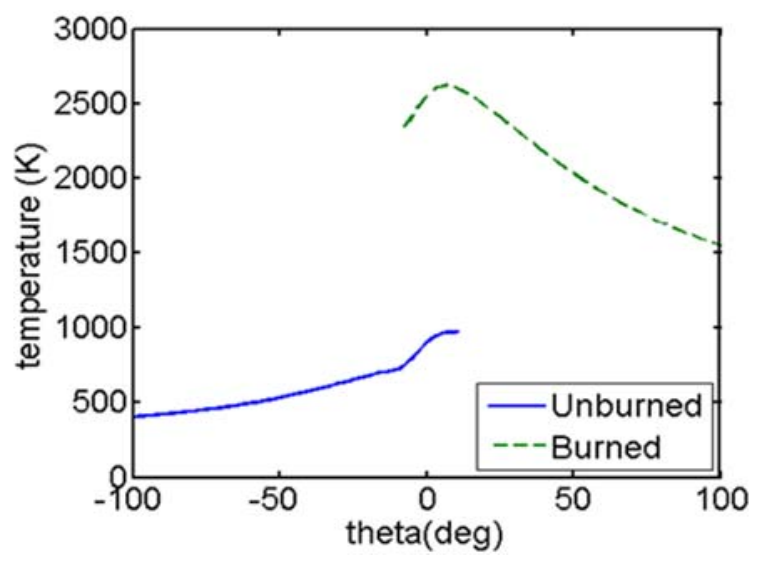

Fig.7. Temperature variation versus crank angle.

Temperature variation for burned and unburned fractions versus crank angle is computed using the developed code. The results are presented in Fig.7. As it can be seen in Fig.7, maximum temperature during the cycle of equivalent engine is $2620 \mathrm{~K}$.

Work performed and heat release during the equivalent engine cycle, are shown in Fig.8 and Fig.9, respectively. 


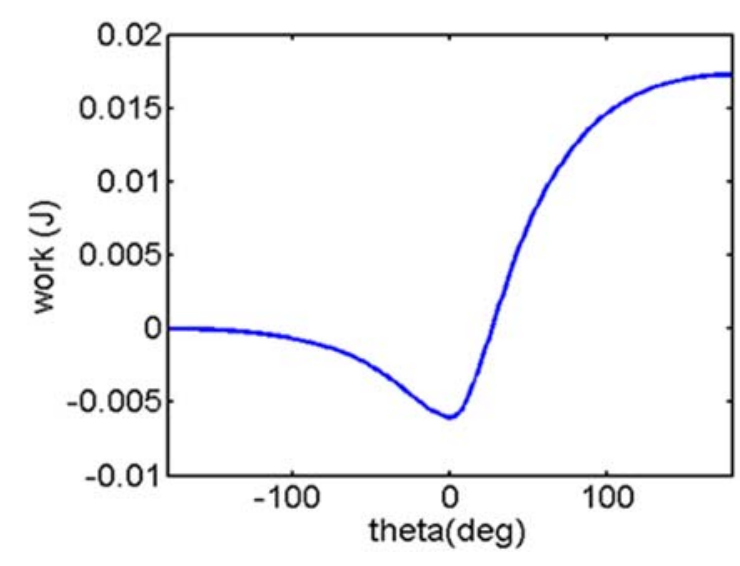

Fig. 8. Work done versus crank angle.

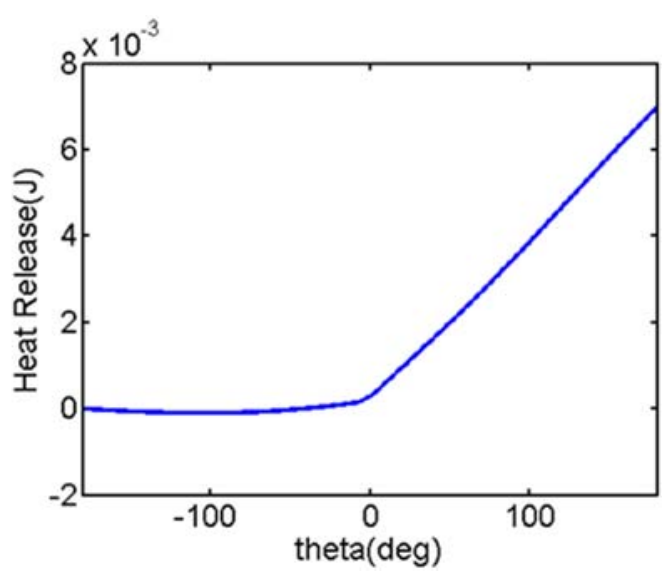

Fig. 9. Heat released versus crank angle.

\section{Conclusions}

A two-zone combustion model is developed for a spark ignition axial vane rotary engine in this paper. Since no experimental data for the AVRE is available at this time, estimates of parameters such as combustion duration, cylinder wall temperature, and intake air temperature have been made. Spark ignition engine cycle simulation has been performed on the equivalent four stroke reciprocating engine of the AVRE engine, with approximately the same cylinder volume variation versus crank angle as this rotary engine. As it has been shown, the developed code could estimate engine pressure variation with good accuracy. Key parameters of the equivalent engine have been computed using the developed code efficiently and can be used in future research on this type of rotary engine. When experimental data become available, fine tuning of the model will be achieved by varying the wall temperature, combustion duration, and the weighting of the premixed and diffusive components of combustion. Future work will focus on fine tuning this model. When this is achieved, the model will have uses other than those previously mentioned. Specifically, the effect of changing the ignition timing can be studied. An ignition lag model may be incorporated into the code to further enhance the predictive ability of the program. The end result of this model is to use the output from the analysis as the input to other models as discussed in the Introduction. The pressure, temperature, and heat transfer coefficients can be used in a finite element analysis of the engine to improve the estimation of the chamber wall temperatures.

\section{Nomenclature}

$$
\begin{aligned}
A_{b} & - \text { burned part area } \\
A_{c} & - \text { cylinder area } \\
A_{u} & - \text { unburned part area } \\
C & - \text { blowby coefficient } \\
c_{p b} & - \text { constant pressure specific heat of the burned part } \\
c_{p u} & - \text { constant pressure specific heat of the unburned part } \\
h & - \text { total specific enthalpy } \\
h_{b} & - \text { specific enthalpy of the burned part } \\
h_{u} & - \text { specific enthalpy of the unburned part } \\
H_{1} & - \text { total enthalpy of the mass loss due to blowby } \\
h_{1} & - \text { specific enthalpy of the mass loss due to blowby } \\
K_{i} & - \text { equilibrium constant } \\
m & - \text { mass }
\end{aligned}
$$




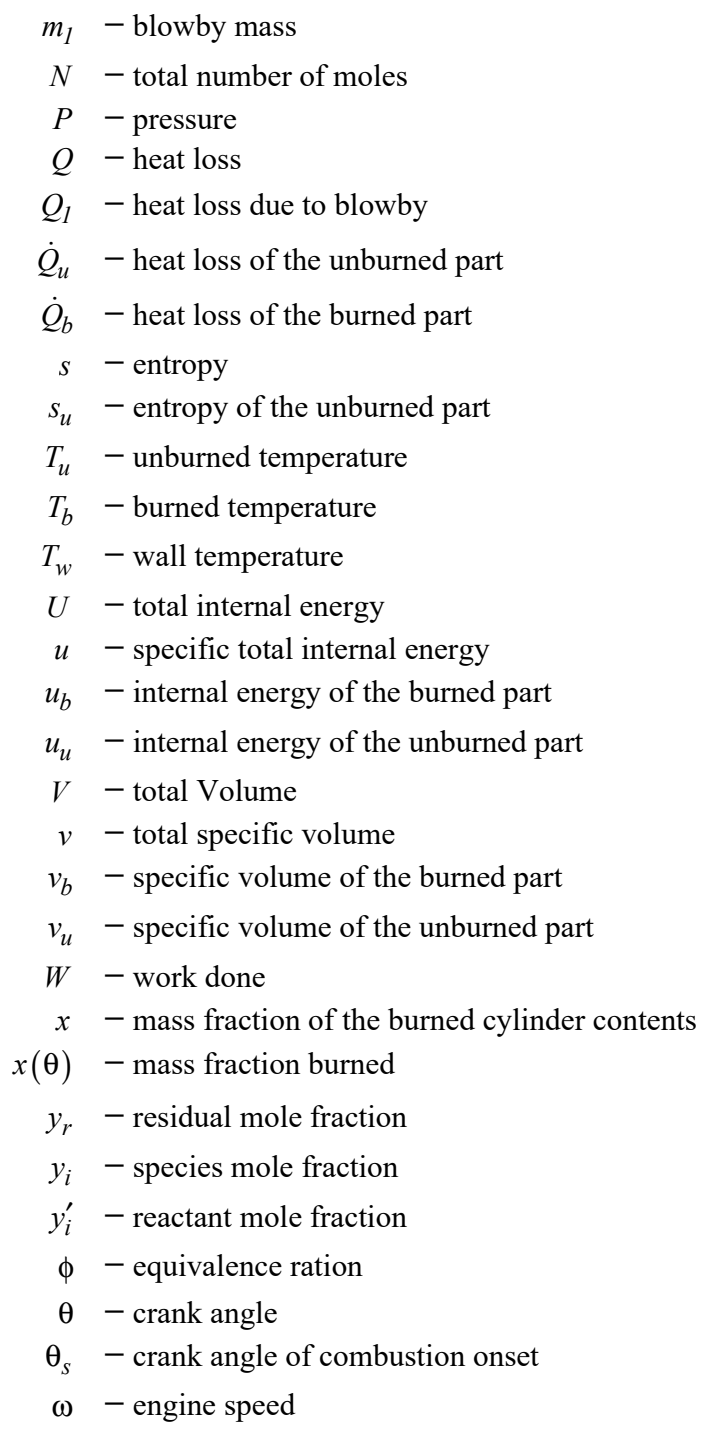

\section{References}

[1] Patel C.K., Shukla D.D., Patel B.A., Solanki N. and Barot M.C. (2015): Combustion modeling of SI engine for predicting behavior of I.C. engine: a review.- International Journal of Advance Research in Engineering, Science \&Technology (IJAREST), vol.2, ISSN(O), pp.2393-9877, ISSN(P), pp.2394-2444.

[2] Chaudhari A.J., Sahoo N. and Kulkarni V. (2014): Simulation models for spark ignition engine: a comparative performance study.- Energy Procedia, vol.54, 2014, pp.330-341.

[3] Sezer I. and Bilgin A. (2014): Exergetic analysis of using the gaseous fuels in spark ignition engines.- Journal of Thermodynamics and Heat Transfer, vol.28, pp.347-355.

[4] Amaya F.D. and Torres G.D. (2014): First and second thermodynamic law analyses applied to spark ignition engines modeling and emissions prediction.- International Journal on Interactive Design and Manufacturing (IJIDeM), vol.17, pp.1-15.

[5] Nagamani G.V. and Sreelatha K. (2015): Computation fluid dynamics simulation of spark ignition engine for gaseous fuels by varying crank angles.- International Journal and Magazine of Engineering, Technology, Management and Research, p.375, ISSN No.2348-4845.

[6] Cuddihly J.L. (2014): A user-friendly, two-zone heat release model for predicting spark-ignition engine performance and emissions.- MSc Thesis, College of Graduate Studies, University of Idaho. 
[7] Adibi-Asl H., Fraser R.A. and McPhee J. (2015): Math-based spark ignition engine modelling including emission prediction for control applications.- International Journal of Vehicle Systems Modeling and Testing, vol.10, No.2, doi:10.1504/ijvsmt.2015.068977, p.148.

[8] Wuo, H. (2013): Study of spark ignition engine combustion model for the analysis of cyclic variation and combustion stability at lean operating conditions.- Master's Thesis, Michigan Technological University, p.76.

[9] Adibi-Asl H., Masoudi R., Fraser R. and McPhee, J. (2014): Symbolic sensitivity analysis of math-based spark ignition engine with two-zone combustion model.- SAE Technical Paper, ISSN: 2688-3627, DOI:https://doi.org/10.4271/2014-01-1072.

[10] Rezapour K., Mason B.A., Wood A.S. and Ebrahimi M.E. (2014): Bi-fuel SI engine model for analysis and optimization.- Universal Journal of Mechanical Engineering, vol.2, pp.71-82.

[11] Abu-Nada E., Al-Hinti I., Al-Sarkhi A. and Akras B. (2006): Thermodynamic modeling of spark- ignition engine: Effect of temperature dependent specific heats.- International Communications in Heat And Mass Transfer, vol.33, pp.1264-1272.

Received: December 19, 2020

Revised: February 3, 2021 